\title{
A INCLUSÃO SOCIAL DAS PESSOAS NA CONDIÇÃO DE REFUGIADO NO BRASIL À LUZ DOS DIREITOS HUMANOS
} \\ Mara Ahlert \\ Universidade de Santa Cruz do Sul - UNISC - Brasil \\ Alcione de Almeida \\ Universidade de Santa Cruz do Sul - UNISC - Brasil
}

\section{Resumo}

Há décadas ocorre o deslocamento de pessoas de um país para outro com o intuito de se proteger de guerras e conflitos armados, perseguições por motivos religiosos, políticos, étnicos. No Brasil há legislação específica que trata sobre o reconhecimento dos refugiados, garantindo a estes a proteção na condição de refugiado. Observa-se que na prática a situação de uma pessoa que se encontra em situação de refúgio é de extrema vulnerabilidade, visto que na vasta maioria das vezes não apresenta condições para sobrevivência de forma digna. $\mathrm{O}$ artigo objetiva analisar a situação das pessoas na condição de refugiado à luz dos direitos humanos, visto que este é um problema de conjuntura internacional e a preocupação está no fato que o número de refugiados aumenta ano após ano. No Brasil existe a Lei $\mathrm{n}^{\circ} 9.474$ de 22 de julho de 1997, no qual constam as condições para o reconhecimento sob a condição de refugiado em solo brasileiro. Aliado ao aumento do número de refugiados, os organismos internacionais não estão conseguindo efetivamente lidar e apresentar soluções com a problemática que envolve o tema.

Palavras-chave: dignidade da pessoa humana, direitos humanos, inclusão, refugiados.

\section{CONSIDERAÇÕES INICIAIS}

O refúgio é e se manterá sendo tema preocupante a nível social e governamental, especialmente por se verificar o aumento do número de pessoas que buscam este recurso para manterem a sua sobrevivência.

Um país que acolhe um refugiado está tendo uma postura humanitária e de solidariedade, destacando que desde a metade do século XX houve um aumento no número de indivíduos na condição de refugiado.

Lamentavelmente, os direitos podem vir a ser violados, seja para um indivíduo ou para uma coletividade. Se analisarmos detalhadamente percebe-se que garantir os direitos humanos às pessoas e fazer com que ocorra a efetivação desses direitos é mais complexo ainda. 
Quando abordamos o assunto sobre refugiados há de ter claro que os aspectos que fazem com que uma pessoa tenha que se submeter a essa condição são situações extremas, as quais envolvem perseguições em virtude de sua raça, credo, opção política, entre outras.

O ACNUR - Alto Comissariado das Nações Unidas para Refugiados, com sede na cidade de Genebra foi criado com o intuito de enfrentar a problemática que envolve o número elevado de pessoas que precisam de amparo e que não podem mais contar com a proteção de seus países de origem. O ACNUR trabalha para garantir a permanência do refugiado em determinado Estado, com autorização do país em que foi recebido, inclusive busca auxiliar os refugiados a obter subsídios materiais até que consiga ter as condições mínimas para sua manutenção no país em que foi abrigado.

Em decorrência dos tratados internacionais criados entre países surgiu uma visão mais humanitária e solidária em relação a pessoa submetida à condição de refugiado, conforme será aferido no decorrer deste artigo.

Entretanto, a situação dos refugiados vem se tornando crescentemente uma crise humanitária de âmbito internacional em proporções jamais estimadas e, em decorrência desta problemática verifica-se que lideranças governamentais carecem de vontade suficiente para executar planos e ações contundentes e efetivas para acolher os refugiados.

No Brasil observamos que existe a Lei $n^{\circ} 9.474$ de 22 de julho de 1997, na qual estão definidos os mecanismos para a implementação do Estatuto dos Refugiados de 1951, no qual constam as condições para o reconhecimento sob a condição de refugiado, bem como, os deveres e direitos inerentes a este indivíduo.

Sob a ótica dos Direitos Humanos o artigo abordará os princípios constitucionais que protegem o refugiado no Brasil, dentre eles o princípio da dignidade da pessoa humana e o princípio da solidariedade, enfatizando que, tendo uma legislação que reconhece a figura do refugiado, nada mais justo que esta pessoa tenha a garantia de uma vida digna no Brasil.

Segundo Alarcón (2016), o Brasil acolhe refugiados, entre eles especialmente refugiados sírios, os quais são acolhidos em decorrência do recrudescimento do conflito nesse país, conforme aponta a Resolução Normativa número 17, de outubro de 2013, emanada do CONARE - Comitê Nacional para os Refugiados. A referida Resolução retira os trâmites burocráticos que podem embaraçar a emissão de vistos para os sírios que pretendem requerer refúgio em solo brasileiro. Atualmente os sírios são o maior grupo de refugiados acolhidos no Brasil. 
Urge a necessidade de se ampliar a proteção às vítimas das perseguições, que abandonam sua residência, seu trabalho, suas famílias e suas propriedades para procurar refúgio em outros Estados, sendo necessário que se evite que estas pessoas sejam expostas à exploração, ao descaso e ao abandono.

Em última análise o estudo aponta a necessidade de se buscar solução para oferecer aos refugiados condições mínimas para a manutenção de uma vida digna, visto que estas pessoas estão expostas à miséria extrema.

\section{BREVES DEFINIÇÕES SOBRE A CONDIÇÃO DE REFUGIADO SOB A ÓTICA DOS DIREITOS HUMANOS}

Inicialmente, há de conceituar que o refugiado pode ser descrito como sendo a pessoa que em função de temores de perseguição por meio dos mais diversos motivos, sejam eles relacionados a sua raça, nacionalidade, opção religiosa, associação a determinado grupo social ou opção política, encontra-se fora de seu país de origem, não podendo regressar a ele por temer sua integridade.

Além do mais, há também as pessoas que são obrigadas a buscarem refúgio em outro país em razão de questões ambientais, citando-se os fatos da natureza, tidos como tragédias ambientais.

$\mathrm{Na}$ qualidade de refugiado também estão inseridos homens e mulheres, incluindo idosos, jovens e crianças.

A definição de refugiado foi objeto de estudo realizado por Talavera e Moyano (2002, p. 317), vejamos:

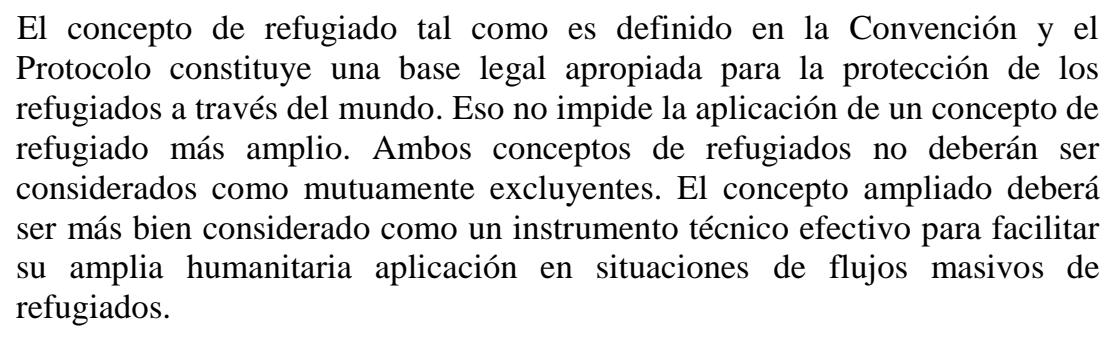

Segundo Guerra (2016, p. 12):

De fato, o refúgio é um instituto que persiste ao longo dos anos em razão dos vários problemas que afligem indivíduos, que acabam tendo a necessidade de promover a troca de ambientes para manter a esperança de continuar vivos. 
O refúgio tem o significado de asilo, abrigo, amparo, apoio. Assim, sendo, o ato de conceder refúgio consiste na concessão de abrigos, amparo, proteção ao indivíduo que foge de seu país de origem porque naquele país não lhe é mais conferida a proteção que necessita.

Em relação ao movimento migratório das pessoas que buscam refúgio, Guerra (2016, p. 5) sustenta que:

o movimento migratório manifesta-se de forma intensa, especialmente em direção aos países desenvolvidos. Tal fato tem provocado manifestações contrárias de vários segmentos da sociedade civil4, sendo certo que isso ocorre de maneira mais acentuada em algumas regiões do planeta, principalmente, em razão da eclosão de guerras civis, problemas étnicos ou religiosos, conflitos armados e também por questões ambientais.

E acrescenta:

Com efeito, a migração contínua e maciça de grande número de pessoas tem produzido sérias consequências, tanto do local de onde provieram como também para o local de chegada7. Todavia, apesar das dificuldades que são observadas, desde a saída até a chegada ao destino final, o número de refugiados tem aumentado de maneira significativa em vários cantos do planeta, posto que as pessoas se deslocam com a esperança de se instalar em determinado Estado para dar início a uma "nova vida", sem pressões, contratempos, ameaças, enfim, sem os perigos que se manifestavam em seus países de origem. (GUERRA, 2016, p. 5)

Expondo a situação e a magnitude da situação que se acentua em relação aos refugiados, não podendo apenas se apresentar dados estatísticos crescentes sem a busca efetiva por soluções afirma-se que:

"É notório que esta definição não se adapta facilmente à magnitude, escala e natureza de muitos dos atuais conflitos ou situações de violência e dos movimentos dos refugiados, evidenciando que o conceito de refugiado não é e não pode ser considerado um conceito estático, tal qual nenhuma norma ou conceito jurídico o é. O Direito é, pois, uma expressão constante da experiência social de modo que as normas refletem comportamentos e fatos sociais e não o contrário, sob risco de ficarem caducas e ineficazes. Assim, é preciso ter atenção aos casos empíricos que evidenciam que há muitas outras pessoas deslocadas que não estão incluídas nas atuais definições de refugiado, todavia também não estão excluídas. Cite-se aquelas pessoas que deixaram seus países de origem em razão de situações terríveis, como miséria econômica generalizada, fragilidade democrática e tantas outras formas de violação ou restrição a direitos fundamentais, mas que não são consideradas oficialmente refugiadas, vez que estas situações não são vislumbradas no regime atual." (WALDELY; VIRGENS; ALMEIDA, 2014)

Sob a conjuntura dos Direitos Humanos, Alarcón (2016) sustenta que em determinados momentos o Direito deve ser observado sob o prisma da sua inserção cultural e do seu lugar na conjuntura histórica, o Direito é considerado um fenômeno histórico, e por sua consequência é composto por uma construção humana susceptível de mudanças e em constante evolução. 
Verifica-se que o Direito está em constante evolução e acompanha as diversas transformações das realidades humanas, sendo necessário estabelecer regramentos no sentido de ordenar as constantes evoluções da sociedade, aproximando-as das vivências e dos valores, não esquecendo do sentido ético que repousa na nossa noção sobre a humanidade.

O Direito pode ser visto como o reflexo de um processo no qual as pessoas buscam criar uma solução para o funcionamento e o convívio em sociedade. Consequentemente o modelo idealizado fundamenta-se em valores e objetivos imediatos, a médio ou longo prazo, para o qual dispõe de um conjunto institucionalizado de órgãos e regras procedimentais.

No decorrer dos anos, de um modo geral, as legislações passaram a consagrar mais direitos em relação aos indivíduos em situações menos vantajosas, isto consiste numa proteção adequada, integral e efetiva do ser humano. Aliado a isso, passou-se a constatar que os valores como a legalidade, a igualdade, a democracia, a justiça, entre outros, reclamam efetividade plena.

Alarcón (2016) argumenta que essa preocupação de amparo ao ser humano nas situações mais difíceis firmou-se tendo como gênese movimentos políticos de forte impacto no jurídico, na morfologia dos Estados e nas relações entre o estado e a sociedade.

Em relação ao Direito Internacional o Alarcón (2016, p. 222) sustenta:

Sem abandonar as conquistas constitucionais, veja-se como também o Internacionalismo, numa progressão necessária e salutar, originou campos de normatividade complexa e vigorosa no mesmo sentido.

Em relação ao Direito de Assistência Humanitária, Amaral Júnior (2003, p. 183) explica que a doutrina francesa costuma distinguir entre:

(...) a intervenção por humanidade, que tem por escopo substrair ao domínio de um governo ou de uma facção os seres humanos ameaçados de morte em um país estrangeiro, da intervenção humanitária, que visa fornecer abrigo, vestuário, assistência médica e sanitária às populações locais, sem que haja qualquer ato de interposição entre as populações e os responsáveis pela sua situação aflitiva.

No que tange o direito dos refugiados, Alarcón (2016, p. 223) sustenta:

Nesse conjunto de blocos normativos, outra ramificação é composta pelo chamado Direito dos Refugiados, que especialmente hoje adquire uma singela, porém firme autonomia. Este se posiciona como disciplina que objetiva promover o dever de amparo da sociedade internacional, e dos Estados em particular, aos povos e pessoas ameaçadas em circunstancias político-militares, culturais ou econômico-sociais adversas, por governos, grupos armados ou forças que por qualquer via atentem contra seus direitos mínimos, especialmente contra a sua vida.

Segundo Alarcón (2016), pode-se aferir que as estruturas jurídicas são diversas, mas, no entanto, não são desconexas nem confusas, senão limítrofes e susceptíveis de se tocarem. E em cada campo encontramos dinâmicas de amparo que atendem circunstâncias diferentes. 
Dessa forma, é possível referir que tanto na perspectiva do Direito Constitucional quanto na perspectiva do Direito Internacional, estes direitos orientam-se pela aplicação da norma mais favorável ao ser humano. Isto é, a aplicação do princípio denominado prohomine.

Grau (2004, p. 39), seguindo essa linha de pensamento enfatiza:

Deve, seguindo essa direção, se aplicar sempre a norma mais ampla, outorgando máxima efetividade aos direitos em questão no caso a ser resolvido. A realização do Direito impende, concomitantemente, a mínima restrição dos mesmos direitos no mesmo caso, através de um delicado, mas necessário, juízo de ponderação no qual o juiz deverá atender postulados do Direito posto e do Direito pressuposto.

Assim, por essa razão, o texto constitucional e os tratados de direitos humanos fazem parte de um mesmo sistema de amparo e proteção ao ser humano. Cabe ao juiz através da análise profunda do caso extrair a norma de decisão mais adequada e ajustada aos princípios que orientam o ordenamento jurídico.

Ainda sobre a internacionalização dos direitos humanos Guerra (2014, p. 287) destaca:

Esse processo de internacionalização dos direitos humanos influenciou sobremaneira o legislador constituinte ao consagrar um rol significativo de direitos fundamentais, elevando à dignidade da pessoa humana a status privilegiado na ordem constitucional brasileira.

Observando os direitos humanos que envolvem o tema, Alarcón (2016, p. 227) acrescenta:

Hoje, a valiosa caracterização jurídica do refúgio impõe reconhecer como alvo da tutela protetora aos perseguidos ou fugitivos de conflitos, que são regularmente pessoas anónimas. Seja qualquer que seja a condição do indivíduo - anônimo ou conhecido - a interpretação ampliativa orienta-se à máxima eficácia de um direito humano, reconhecido na ordem interna da maior parte dos Estados do mundo como um direito fundamental.

Dessa forma, há de se destacar que a dignidade humana, a vida e a segurança são alguns dos valores que constituem o transfundo da normatividade nacional e internacional com relação aos problemas humanitários e, em particular, ao problema do refúgio, razão pela qual o tema é tão relevante e objeto de estudo por filósofos, sociólogos, advogados, entre outros. 


\section{AS DIMENSÕES DO DIREITO DOS REFUGIADOS E OS PRINCIPAIS ASPECTOS SOBRE A LEI N $\mathbf{N}^{\circ}$ 9.474/97 QUE CRIA O COMITÊ NACIONAL DOS REFUGIADOS}

Segundo Alarcón (2016, p. 220), os informes do ACNUR - Alto Comissariado das Nações Unidas para Refugiados - de março de 2016, retratam que:

(...) mais de um milhão e trezentas mil pessoas oriundas da Síria, Afeganistão e Iraque cruzaram fronteiras europeias. Entretanto, expõe o próprio ACNUR, a crise não é apenas de refugiados, mas de solidariedade dos Estados de Europa, cujas lideranças governamentais carecem de vontade suficiente para executar planos e ação contundentes e efetivos para acolher os migrantes forçados.

Não há como negar que a agressividade das potências e as intervenções de organismos internacionais agravaram a situação dos refugiados nas últimas décadas.

Segundo Alarcón (2016), atualmente vivem no Brasil cerca de 7.000 mil refugiados de várias nacionalidades diferentes. Deles, mais de 400 indivíduos são reassentados, isto quer dizer que são originários de Estados nos quais obtiveram refúgio, mas onde, as forças que os perseguiam e que os obrigaram a deslocar-se forçadamente do seu país de origem conseguiram chegar ameaçadoramente.

Guerra (2014, p. 14) enfatiza:

Evidencia-se, pois, uma grande preocupação do Brasil em relação aos direitos humanos, tanto de seus nacionais, como dos estrangeiros. Pelo fato de se considerar um país de imigração aberta, o Brasil acolheu milhares de estrangeiros ao longo de sua existência.

O Brasil é um dos membros fundadores do comitê do ACNUR, tendo ratificado, em 1960, a Convenção relativa ao Estatuto dos Refugiados de 1951.

Importante destacar que o ACNUR possui sua sede em Brasília e é composto por representantes dos respectivos órgãos:

\footnotetext{
"Ministério da Justiça, que o preside; Ministério das Relações Exteriores, que exerce a vice presidência; Ministério do Trabalho e do Emprego; Ministério da Saúde; Ministério da Educação e do Desporto; Departamento da Polícia Federal; Organização não governamental, que se dedica à atividade de assistência e de proteção aos refugiados no País (Cáritas Arquidiocesana de São Paulo e Rio de Janeiro); Alto Comissariado das Nações Unidas para os Refugiados - ACNUR, com direito a voz, sem voto.” (GUERRA, 2016, p. $15)$.
}

Já o Comitê Nacional para os Refugiados - CONARE, possui o objetivo de analisar as solicitações sobre o reconhecimento da condição de refugiado, bem como, deliberar quanto à cessação ex officio ou mediante requerimento das autoridades competentes da condição de refugiado; declarar a perda da condição de refugiado; orientar e coordenar as ações Barbarói, Santa Cruz do Sul, Edição Especial n.47, p.<09-21>, jan./jun. 2016 
necessárias à eficácia da proteção, assistência, integração local e apoio jurídico aos refugiados, com a participação dos Ministérios e instituições que compõem o CONARE; aprovar instruções normativas que possibilitem a execução da Lei n. 9.474/97.

Assim, verifica-se que no Brasil a matéria que trata sobre refugiados está disposta na Lei n. 9.474, de 22 de julho de 1997, a qual criou o CONARE, órgão colegiado e, conforme dito, está vinculado ao Ministério da Justiça que reúne órgãos representativos da área governamental, da sociedade civil e das Nações Unidas.

A Lei n. 9.474, de 22 de julho de 1997 considera refugiado:

Art. $1^{\circ}$ Será reconhecido como refugiado todo indivíduo que:

I - devido a fundados temores de perseguição por motivos de raça, religião, nacionalidade, grupo social ou opiniões políticas encontre-se fora de seu país de nacionalidade e não possa ou não queira acolher-se à proteção de tal país;

II - não tendo nacionalidade e estando fora do país onde antes teve sua residência habitual, não possa ou não queira regressar a ele, em função das circunstâncias descritas no inciso anterior;

III - devido a grave e generalizada violação de direitos humanos, é obrigado a deixar seu país de nacionalidade para buscar refúgio em outro país.

Destaca-se que esta lei se estende ao cônjuge, aos ascendentes e descendentes e demais membros do núcleo familiar que dependem economicamente do refugiado para sua subsistência.

Nessa ótica, observando a legislação brasileira percebe-se que nos dias atuais o direito dos refugiados possui proteção no direito brasileiro, eis que estão estabelecidas as condições necessárias à obtenção da qualidade de refugiado e há o compromisso firmado entre poderes públicos nacionais e a ordem internacional na busca da efetivação dos direitos fundamentais das pessoas em refúgio.

No entanto, as pessoas que cometeram crimes contra a paz, crimes de guerra ou contra a humanidade, ou que tenham cometido crime hediondo, participado de atos terroristas ou tráfego de drogas, não terão reconhecida a condição de refugiado.

A Lei $n^{\circ}$ 9.474/97 também aponta as situações em que o indivíduo terá cessada sua condição de refugiado. Vejamos o disposto no artigo 38, in verbis:

Art. 38. Cessará a condição de refugiado nas hipóteses em que o estrangeiro:

I - voltar a valer-se da proteção do país de que é nacional;

II - recuperar voluntariamente a nacionalidade outrora perdida;

III - adquirir nova nacionalidade e gozar da proteção do país cuja nacionalidade adquiriu;

IV - estabelecer-se novamente, de maneira voluntária, no país que abandonou ou fora do qual permaneceu por medo de ser perseguido;

V - não puder mais continuar a recusar a proteção do país de que é nacional por terem deixado de existir as circunstâncias em consequência das quais foi reconhecido como refugiado; 
VI - sendo apátrida, estiver em condições de voltar ao país no qual tinha sua residência habitual, uma vez que tenham deixado de existir as circunstâncias em consequência das quais foi reconhecido como refugiado.

Diante da observação constante no inciso VI, o qual menciona o termo apátrida, esclarece-se que as pessoas nesta condição são indivíduos desprovidos de pátria, sem nacionalidade. Consequentemente, não estão sob a jurisdição de nenhum Estado, não recebendo proteção jurídica por parte de nenhum país.

Dessa forma, o indivíduo considerado apátrida é aquele que não possui nacionalidade ou cidadania, pois o elo que havia entre o Estado e a pessoa se rompeu. Certamente a pessoa nestas condições está exposta a uma série de dificuldades, visto que não encontra acesso a serviços de saúde e educação, direitos de propriedade e de exercer livremente o direito de ir e vir. A tendência é que em virtude de sua situação os apátridas venham a se tornar pessoas marginalizadas.

O artigo 39 refere hipóteses de perda da condição de refugiado poderá se dar por renúncia deste e em razão de prática de ato reprovável, ocasião em que o Brasil não desejará mais oferecer proteção a este indivíduo por meio da concessão de refúgio.

A situação que envolve a perda ou cessação da condição de refugiado é proferida em primeira instância, pelo CONARE, através de deliberação junto ao órgão. A decisão sobre a perda ou cessação da condição de refugiado é passível de recurso e o qual será apreciado pelo Ministro de Estado da Justiça.

Ao final, observa-se que o Brasil possui uma legislação específica sobre o tema e demonstra preocupação com a situação dos refugiados e a efetivação dos seus direitos em território nacional.

\section{OS PRINCÍPIOS CONSTITUCIONAIS E A PROTEÇÃO DO REFUGIADO NO BRASIL}

Segundo Alarcón (2016), em decorrência da internacionalização e do sentido universal dos Direitos Humanos, o assunto que envolve o refúgio constitui uma problemática jurídicocientífica na qual se encontram as formulações do constitucionalismo e do internacionalismo.

Certamente a dignidade humana, a vida e a segurança são alguns dos valores mais importantes e vem protegidos através da normatividade nacional e internacional com relação aos problemas humanitários e, em particular, ao problema do refúgio. 
Por esta razão deve-se primar pelo amparo às pessoas em qualquer circunstância ou diante de qualquer tragédia, sendo essencial que se busque a efetividade dos direitos fundamentais e dos princípios dignidade da pessoa humana e da solidariedade.

A Constituição Federal de 1988 consagrou diversos direitos que não eram apontados nas constituições anteriores. Dessa forma, convém examinar alguns princípios norteadores do texto constitucional que podem ser invocados em favor da pessoa refugiada ou requerente do refúgio.

\title{
4.1 O princípio da dignidade da pessoa humana
}

Sobre o tema que trata da dignidade da pessoa humana Alarcón (2016, p. 233) descreve:

\begin{abstract}
Em época recente a doutrina do campo constitucional se deteve na análise mais aprimorada do princípio da dignidade da pessoa humana. No Brasil, para além da sedução acadêmica do tema, que tem implicações no campo da Ética, da Filosofia do Direito, da Bioética e de outras disciplinas científicas, a questão implica um tratamento inspirado no artigo $1^{\circ}$, inciso III da Carta de 1988, que a consagra como um dos fundamentos do Estado Democrático de Direito.
\end{abstract}

A proteção entre as pessoas prevê que todas são igualmente dignas, isto significa a impossibilidade de reduzir as condições de vida do ser humano a um patamar tal que se provoque sua degradação ou a submissão a condições de vida de extrema miséria ou exploração. Enfim, este princípio supõe que o Direito tem a tarefa de impedir que a pessoa viva em condições indignas.

Sobre a dignidade Márquez (2005, p. 20-21) expõe:

\begin{abstract}
Reconhecer que o homem tem dignidade é reconhecer que tem umas exigências que lhe são devidas, uns direitos que lhe pertencem. O homem tem dignidade e este não é um factum de caráter empírico nem um teorema que seja possível demostrar matematicamente, porque também não é realidade nem ideal. Não pertence à ordem ôntica, senão axiológica, não ao é, senão ao deve. Pertence não à ordem das coisas futuríveis, senão ao das valorações, "é uma qualidade que outorgamos, que realça ao homem e o fazemos simplesmente porque sem ela não haveria horizonte moral possivel, moralidade possivel, estaríamos no plano da mera natureza, da animalidade, da faticidade instintiva".
\end{abstract}

Em relação aos refugiados, a dignidade humana pressupõe que este ser humano volte a ter condições mínimas de existência e de liberdade, que lhe seja possível iniciar uma nova vida sem perseguições de qualquer natureza. 


\subsection{O princípio da solidariedade}

Em relação ao princípio da solidariedade Alarcón manifesta $(2016,235)$ :

O princípio é decorrente da leitura do inciso I do artigo $3^{\circ}$ da Constituição. E, realmente, na contemporaneidade as ameaças constantes à paz e ao direito à vida, bem como a necessidade de responder à exclusão social e à discriminação negativa, não permitem deixar de abordar seu conteúdo, de maneira que há que reafirmá-lo como peça chave na procura do respeito pela vida e os direitos fundamentais.

Como se vê, o princípio não é algo estranho ao mundo do Direito. Muito pelo contrário, deve-se descortinar seu conteúdo e importância. E vale reconhecer que, até certo ponto a doutrina, ainda que reconheça sua existência e nexo com a fraternidade emanada da Revolução Francesa, ofereceu muitas vezes, nas suas tentativas de promoção, um tratamento apenas retórico ou exclusivamente atrelado às virtudes éticas.

Os legisladores internacionais entendem que o assunto sobre a solidariedade não está muito claro. Nesse diapasão, Martínez (2001, p. 177) supõe que solidariedade ainda se configura numa aspiração que embasa algumas instituições jurídicas, no entanto, não é uma realidade do Direito positivo, esclarecendo que:

(...) el Derecho internacional de los derechos humanos necesita de nuevos desarrollos desde la perspectiva de la solidaridad y de consideraciones elementales de humanidad, fundamentalmente en el ámbito de las garantías, así como en el reconocimiento de algunos derechos colectivos".

Denota-se, que este princípio ainda é vago para o tema sob análise, sendo mais aceito no campo da ética, o que faz com que traduza a ideia de um dever jurídico nos quais se evidencia o interesse em criar as condições para o equilíbrio social e com o intuito de fomentar o desenvolvimento das potencialidades das pessoas.

\section{Considerações Finais}

De fato, a situação do refugiado no âmbito internacional repercutiu na ordem jurídica brasileira, basta observar a quantidade de compromissos internacionais que o Brasil assumiu em matéria de garantia dos direitos humanos, especial após ter firmado a lei específica que trata sobre o reconhecimento do refugiado em solo brasileiro.

No Brasil o CONARE e o ACNUR têm estado à frente de esforços no sentido de garantir o refúgio aos indivíduos que estão enquadrados no rol do artigo $1^{\circ}$, da Lei $n^{\circ}$ 9.474/97, a qual dispõe quem pode ser reconhecido como refugiado em território brasileiro. 
Obviamente que a situação merece atenção especial por parte dos governantes e legisladores, visto que é necessário que fomente políticas públicas de inclusão dos refugiados na sociedade em que estão sendo inseridos.

Com o intuito de conferir maior proteção e segurança jurídica, diversos documentos internacionais, bem como, no Brasil, legislações internas, traçaram as principais características do refúgio, estabelecendo, além da sua conceituação, os requisitos pertinentes para sua concessão, bem como, a explanação acerca das causas de perda e cessação da condição de refugiado, assim como o procedimento a ser seguido para a sua concessão.

Indiscutível que o instituto do refúgio necessita ser valorizado e avaliado nos dias atuais, tendo em vista que as pessoas na condição de refugiados se encontram em estado de vulnerabilidade, pois necessitam deslocar-se para salvar suas vidas ou preservar sua liberdade.

Além de utilizar-se o tema refugiado para configurar a pessoa que foge de seu país em virtude do temos de perseguições preconceituosas e discriminatórias, há também os motivos econômicos que podem ser caracterizados pela escassez de água, alimentos e outros mantimentos necessários para a manutenção da vida humana.

Em diversas oportunidades esses indivíduos contam com a sua própria sorte, pois não possuem proteção de seu próprio Estado, destacando que em muitos casos é seu próprio governo que é o perseguidor por motivos políticos, religiosos, entre outros. Se não houver o acolhimento destas pessoas em outros Estados, poderão estar fadados à morte.

Pelo exposto, não resta dúvida de que o instituto jurídico do refúgio foi criado com o objetivo de proteger todo e qualquer ser humano que não goze da devida proteção jurídica em seu país de origem.

\title{
THE SOCIAL INCLUSION OF PEOPLE IN THE CONDITION OF REFUGEES IN BRAZIL IN THE LIGHT OF HUMAN RIGHTS
}

\begin{abstract}
For decades the displacement of people from one country to another in order to protect themselves from wars and armed conflicts, persecution for religious reasons, political, ethnic. In Brazil there is specific legislation which deals with the recognition of refugees, ensuring them the protection in refugee status. It notes that in practice the situation of a person who is in refuge situation is extreme vulnerability because the vast majority of the time does not have conditions for survival with dignity. The article aims to analyze the situation of people in the refugee status in the light of human rights, since this is an international environment problem and concern is the fact that the number of refugees increases year after year. In Brazil there is the Law No. 9474 of July 22, 1997, which set out the conditions for recognition under refugee status in Brazilian soil. Coupled with the increasing number of refugees, international
\end{abstract}


organizations are failing to deal effectively and provide solutions to the problems surrounding the issue.

Keywords: human dignity, human rights, inclusion, refugees.

\section{Referências Bibliográficas}

ACNUR. Refúgio, Migrações e Cidadania. Caderno de Debates 6, Dezembro,2011.

ALARCÓN, Pietro de Jesús Lora. Direitos dos refugiados: uma leitura com fundamento nos princípios constitucionais. Ius Gentium. Curitiba, vol. 7, n. 1, p. 4-21, jan./jun. 2016. JÚNIOR, Alberto do Amaral. O Direito de Assistência Humanitária. Rio de Janeiro. São Paulo: Renovar. 2003.

GRAU, Eros. O Direito posto, o Direito pressuposto e a doutrina efetiva do Direito In O eu é a Filosofia do Direito?. Eros Grau et al. Barueri/SP: Manole. 2004.

GUERRA, Sidney. Direitos humanos na ordem jurídica internacional e reflexos para ordem constitucional brasileira. 2. ed. São Paulo: Atlas, 2014.

GUERRA, Sidney. O instituto jurídico do refúgio à luz dos direitos humanos. Ius Gentium. Curitiba, vol. 7, n. 1, p. 4-21, jan./jun. 2016.

MÁRQUEZ, José Manuel Panea. La imprescindible dignidad In Bioética y Derechos Humanos. Antonio Ruiz de la Cuesta (Coordinador) Sevilla: Universidad de Sevilla. Santander Central Hispano. 2005. P. 17-27.

MARTÍNEZ, Gregorio Peces-Barba. Curso de Derechos Fundamentales. Teoría General. Madrid: Universidad Carlos III de Madrid. Boletín Oficial del Estado, 1999.

TALAVERA, Fabian Novak; MOYANO, Luis Garcia Corrochano. Derecho internacional público. Lima: Fondo Editorial de la PUC, 2002.

WALDELY, Aryadne Bittencourt; VIRGENS, Bárbara Gonçalves; ALMEIDA, Carla Miranda Jordão. Refúgio e realidade: desafios da definição ampliada de refúgio à luz das solicitações no Brasil. REMHU - Rev. Interdiscip. Mobil. Hum., Brasília, Ano XXII, n. 43, p. 117-131, jul./dez. 2014. Disponível em; 〈http://www.scielo.br/ pdf/remhu/v22n43/v22n43a08.pdf>. Acesso em: 20 abr. 2016.

\section{Sobre os autores:}

Mara Ahlert é Advogada e Mestranda em Direito pelo PPGD - UNISC - Conceito Capes 5. Pós-graduada em Docência na Educação Profissional e Formação Pedagógica pela Faculdade Cenecista de Osório - Facos. Bacharel em Direito pela Universidade do Vale do Rio dos Sinos - Unisinos. Endereço Eletrônico: maraahlert@yahoo.com.br

Alcione de Almeida é Advogado e Mestrando em Direito pelo PPGD - UNISC - Conceito Capes 5. Bacharel em Direito pelo Centro Universitário Franciscano - Unifra. Endereço Eletrônico: almeida_advogado@hotmail.com 